\title{
CHEK2 mutations and papillary thyroid cancer: correlation or coincidence?
}

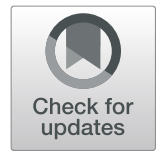

\author{
Kortbeek Koen ${ }^{1 *}$, De Putter Robin ${ }^{2}$ and Naert Eline ${ }^{1}$
}

\begin{abstract}
We report the case of a breast cancer survivor, diagnosed with an underlying CHEK2 c.1100delC heterozygosity, who developed a papillary thyroid cancer 5 years later. A CHEK2 c.1100delC (likely) pathogenic variant is associated with an increased risk of breast, prostate and colorectal cancer and therefore risk-specific screening will be offered. Current national and international screening guidelines do not recommend routine screening for thyroid cancer. Hence, we reviewed the literature to explore the possible association between a CHEK2 mutation and thyroid cancer. A weak association was found between the various CHEK2 mutations and papillary thyroid cancer. The evidence for an association with CHEK2 c.1100delC in particular is the least robust. In conclusion, there is insufficient evidence to warrant systematic thyroid screening in CHEK2 carriers.
\end{abstract}

Keywords: CHEK2, CHEK2 c.1100delC, Papillary thyroid Cancer, Breast Cancer, Thyroid Cancer screening

\section{Introduction}

\section{Case presentation}

In 2014, our patient was diagnosed with cancer of the left breast at the age of 35 . She was treated with a mastectomy accompanied by an axillary lymph node dissection, following a positive sentinel node biopsy. Definitive pathological staging showed a grade 3 invasive ductal carcinoma no special type pT1c pN1a (TNM 7th Edition). Additional pathological characteristics revealed a ki67 of $10 \%$, a positive hormone receptor status and no HER2Neu amplification. She received adjuvant chemotherapy, radiotherapy and 5 years of tamoxifen in combination with a LHRH agonist.

As recommended by national guidelines, genetic screening was performed because of her young age which found a germline heterozygosity for CHEK2 c.1100delC. The gene panel included BRCA1, BRCA2, PALB2 and CHEK2 c.1100delC. Maternal familial history revealed a female with breast cancer at age 48 and a male with prostate

\footnotetext{
*Correspondence: koen.kortbeek@ugent.be

'Department of Medical Oncology, University Hospital Ghent, Ghent, Belgium

Full list of author information is available at the end of the article
}

cancer at age 64, both are third degree relatives. In the paternal family history, there were two cases of a primary brain tumour in a second and third degree male relative. The CHEK2 variant was found to be paternally inherited. Her two sisters were tested and did not share the mutation, further family members have not been tested. Considering the increased risk of contralateral breast cancer associated with this germline CHEK2 mutation, the patient opted for a preventive contralateral mastectomy with bilateral breast reconstruction. (Fig. 1)

In March 2020 clinical examination revealed a cervical adenopathy and a Fluorodeoxyglucose (FDG) Positron Emission Tomography - Computed Tomography (PETCT) was performed, which showed a necrotic adenopathy in region $2 \mathrm{~A}$ right and a heterogeneous, metabolically active lymph node in region 3 right. Excision biopsy of the lesion in region $2 \mathrm{~A}$ revealed a lymph node metastasis of a papillary thyroid carcinoma. A total thyroidectomy with cervical lymph node dissection of the right regions $2-5$ was performed. The pathology report confirmed the presence of an invasive papillary thyroid carcinoma (pT3N1b (TNM 8th Edition)). In June 2020 an adjuvant treatment with $100 \mathrm{mCi} \mathrm{I}^{131}$ was administered 


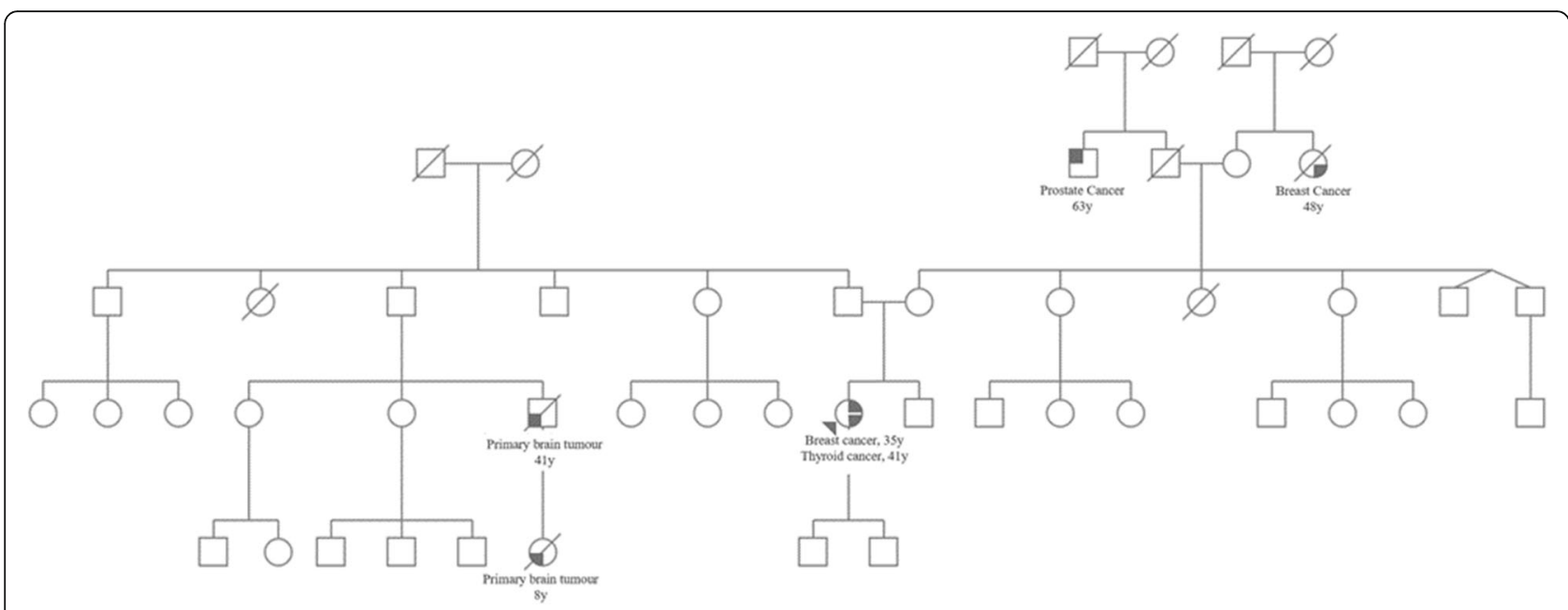

Fig. 1 Case pedigree. Proband indicated with arrow

with curative intent. Until now, there is no evidence of relapse.

This case led us to review the evidence for an association between mutations in $C H E K 2$ and papillary thyroid cancer. In particular, does the CHEK2 c.1100delC mutation convey a higher risk of papillary thyroid cancer and how should we counsel these women?

\section{Background}

CHEK2 is a gene located on chromosome 22q and acts as a tumour suppressor gene. It encodes for the protein CHEK2, the human ortholog of yeast Cds1 and Rad 53, which are G2 checkpoint kinases. DNA double strand breaks lead to activation of ATM kinase, which in turn activates CHEK2 by phosphorylation of the $\mathrm{N}$-terminal regulatory domain. CHEK2 phosphorylates $\mathrm{p} 53$, mediating activation and stabilization of p53 by ATM. CHEK 2 also phosphorylates BRCA1, modulating its function towards homologous recombination DNA repair, as well as several other regulators. As such CHEK2 is a member of the homologous recombination genes involved in the DNA repair pathway [1-3]. (Fig. 2)

The majority of the studies evaluating the risk of cancer conferred by CHEK2 mutations have focused on two CHEK2 variants: c.1100delC and c.470 T > C (p.Ile157Thr, hereafter referred to as I157T), which are most prevalent in the European population. Other founder mutations exist and include c.444 + 1G > A (IVS2 + 1G > A), deletion of exons 9-10 (also known as EX8_9del and del5395) and the Ashkenazi Jewish founder variant c.1283C $>\mathrm{T}$ (p.S428F). Throughout the gene pathogenic truncating, missense, and splicing variants have been documented [3, 4]. (Fig. 3)

CHEK2 c.1100delC is a (likely) pathogenic variant of the CHEK2 gene caused by deletion of a single cytosine. This results in truncation, and loss of CHEK2 activity [5]. Heterozygosity for this mutation is found in 0,5 $1,4 \%$ of the Northern European population [5, 6]. Casecontrol studies found an association with breast, prostate and colorectal cancer [5]. A large meta-analysis found a 3 to 5 times higher risk of breast cancer [5]. Other truncating CHEK2 mutations showed a similar risk [7].

The missense I157T mutation is mainly found in Central European populations with a carrier frequency of 5-6\% [3, 7]. One study found an increased risk of breast, colon, kidney and prostate cancer associated with this variant [7].

\section{Materials and methods}

We performed a comprehensive search using multiple databases (MEDLINE, Embase, Google Scholar, and Web of Science) until 15 February 2021. The search was restricted to studies in English, French, Dutch and

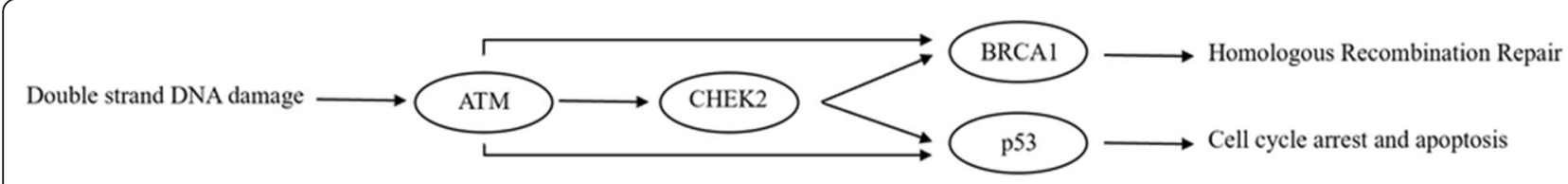

Fig. 2 Simplified ATM-CHEK2-BRCA1 pathway. In the presence of double strand DNA breaks, sensor protein complexes activate ATM. ATM leads to phosphorylation of CHEK2 and p53 stabilization. CHEK2 also phosphorylates p53 and several other proteins contributing to p53 dependent cell cycle arrest, which lead to apoptosis. CHEK2 activates BRCA1 and other regulators by phosphorylation, leading to the formation of homologous recombination repair complexes. Image courtesy of author 


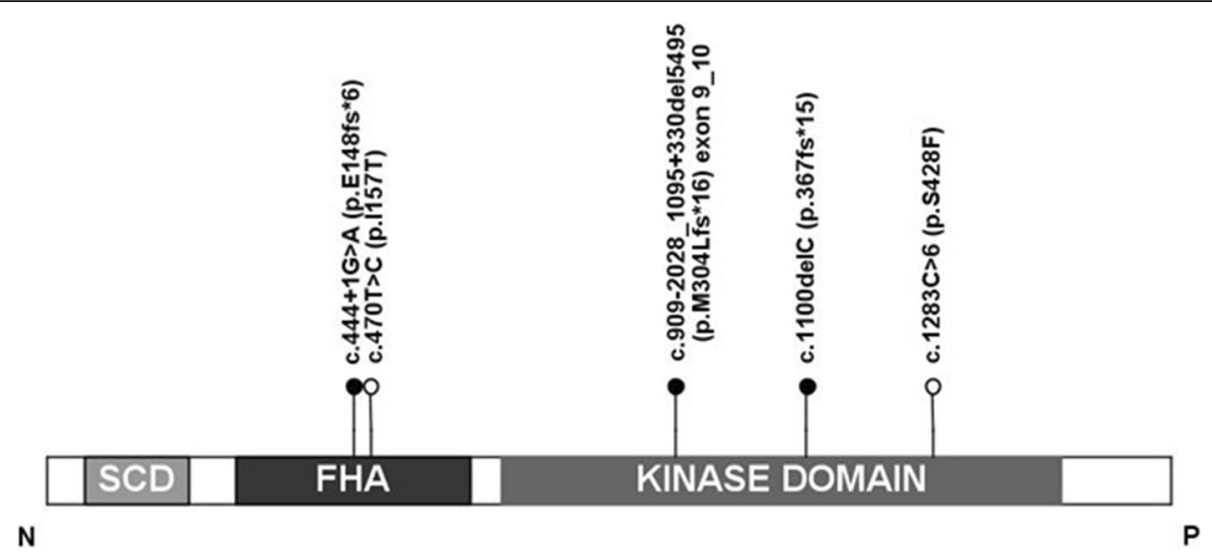

Fig. 3 CHEK 2 protein domains. Lollipops indicate sites of founder mutations (black: truncating; white: missense). (SCD: SQ/TQ cluster domain; FHA: forkhead-associated domain; KD: kinase domain). Image courtesy of author

German. Search terms were "CHEK2", "CHK2", "rad53", and "Thyroid Cancer". Search strategy diagram is provided. Reviews, meta-analyses, case reports, preclinical data and letters were excluded. Studies concerning medullary thyroid cancer were excluded considering the separate genetical background of this pathology. Studies reporting only somatic mutations in thyroid cancer were excluded. One study was rejected because the same dataset was previously included [8, 9]. (Fig. 3 and 4)

\section{Results}

The evidence of a possible association between CHEK2 mutations and papillary thyroid cancer is derived from 5 different types of studies:

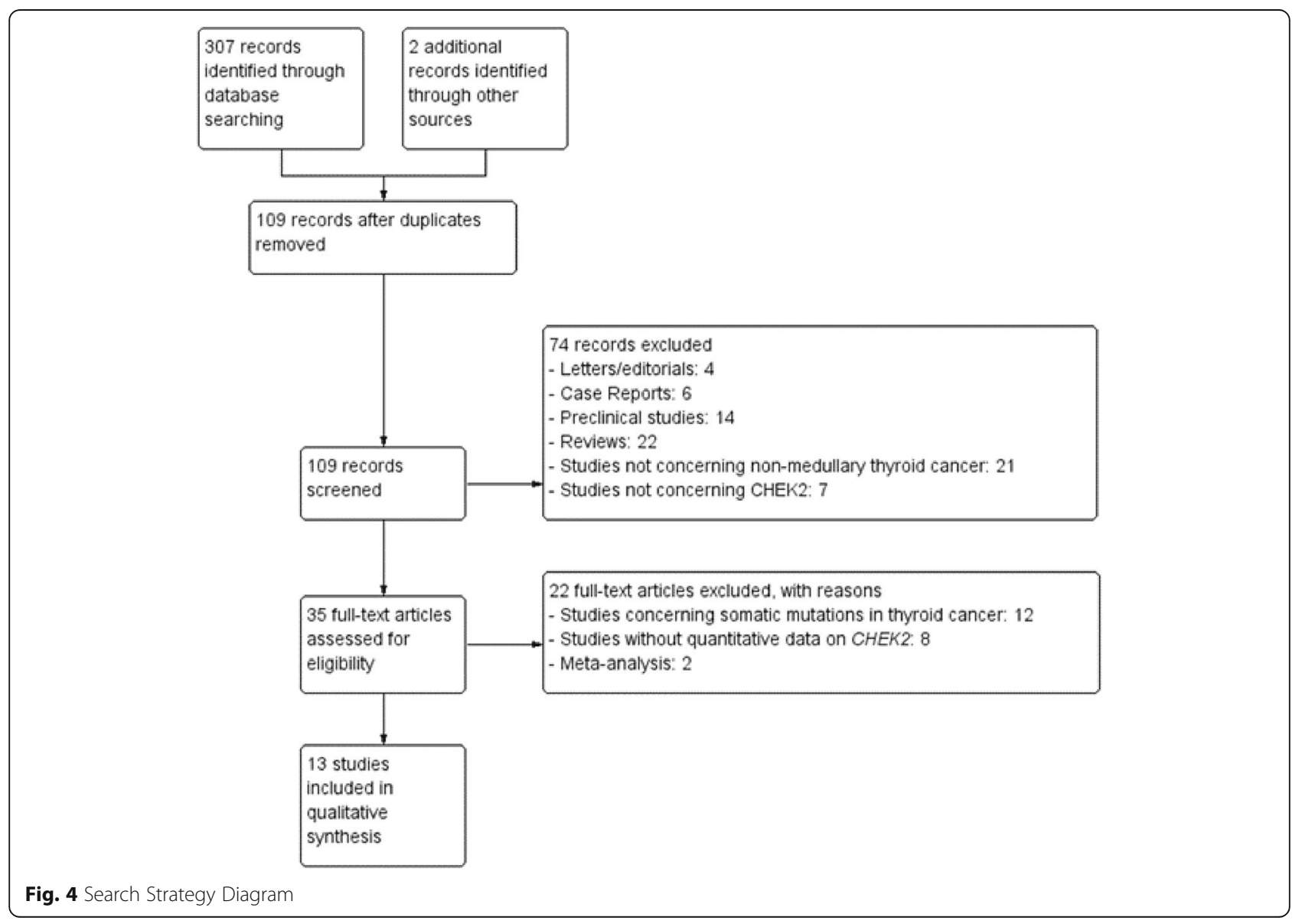


Incidence of papillary thyroid cancer in CHEK2 c.1100delC mutation carriers versus non-carriers

The Copenhagen retrospective cohort study reported the incidence of different types of cancer in a cohort of 670 carriers of a heterozygous CHEK2 c.1100delC mutation in comparison to a cohort of 86.305 non-carriers. Cancer diagnoses were retrieved by linking the individuals to the Danish Cancer Registry. The median follow-up time was 43 years. The incidence of thyroid cancer was slightly higher in the group of CHEK2 c.1100delC mutation carriers $(5 / 670(0,9 \%)$ vs $99 / 86303(0,1 \%))$. The age and sex adjusted hazard ratio (HR) however was not significantly increased (HR 1,26; 95\% CI [0,18 - 9,09]; $p=$ $0,81)[10]$.

A large cross-sectional study evaluated the frequency of different cancer types in germline carriers of (likely) pathogenic CHEK2 variants versus non-carriers. These carriers were identified by multigene panel testing. The reason for multigene panel testing was not disclosed. Frequency of cancer was extracted from the patient history. The population was predominantly female (90\%), with mainly Caucasian (75\%) and Ashkenazi Jew (10\%) ethnicity. This study identified 1101 patients with a CHEK2 (likely) pathogenic variant, $76 \%$ founder and $24 \%$ non-founder variants. The most frequent founder mutations were c.1100delC (49\%), I157T (30\%), S428F (12\%), Ex8_9del (3,5\%) and c.444+1G > A (3,5\%). The frequency of thyroid cancer in CHEK2 mutation carriers (excluding $\mathrm{I} 157 \mathrm{~T}$ ) was $3,7 \%$ compared to $2,1 \%$ in the group of 31,080 non-carriers, which implicates a significantly higher odds ratio (OR) for developing thyroid cancer when a CHEK2 mutation is present (OR 1,77; $95 \%$ CI $[1,15-2,62] ; p=0,01)$. There was no difference in frequency between founder and non-founder mutations. Thyroid cancer histology was not provided [11].

\section{Prevalence of thyroid cancer in CHEK2 c.1100delC mutation carriers versus other CHEK2 mutations}

A recent retrospective study in patients who underwent hereditary cancer multigene panel testing identified 2508 carriers of a pathogenic CHEK2 variant. There were 119 unique CHEK2 variants identified, whereof the most prevalent variants were c.1100delC (31\%), p.I157T (27\%), c. $1283 \mathrm{C}>\mathrm{T}$, deletion exons $9-10(3,4 \%)$, c. $444+1 \mathrm{G}>\mathrm{A}$ (3\%), c. $1427 \mathrm{C}>\mathrm{T}(5 \%)$, c. $349 \mathrm{~A}>\mathrm{G}(4,6 \%)$ and c.190G > A $(3,2 \%)$. The population was mainly Caucasian $(80 \%)$, with about $9 \%$ Ashkenazi Jew ancestry. The frequency of thyroid cancer (histology not specified) was 2,9\% in all variants combined and was not significantly different compared to c.1100delC. The highest frequency of thyroid cancer was reported in c. $444+1 \mathrm{G}>\mathrm{A}(5,8 \%)$ and c.190G > A (5,6\%) carriers [4]. This study lacked a noncarrier control group.

\section{Prevalence of thyroid cancer in germline CHEK 2 carrier case series}

One small study examined the use of ultrasound screening for thyroid cancer in 62 female carriers of CHEK2 truncating mutations (c.1100delC, IVS2 $+1 \mathrm{G}>\mathrm{A}$, del5395). Nodular goiter was diagnosed in $60 \%$, fine needle aspiration was performed in $40 \%$ of all patients and papillary thyroid cancer was subsequently found in $6 \%$ $(4 / 62)$. There was no control group [12]. One conference abstract reported 107 CHEK2 mutation carriers identified through next generation sequencing in a North American Caucasian, mainly female population. The majority of these patients had a history of cancer (59\%), mainly breast cancer. A history of papillary thyroid cancer was reported in $4 \%$. The specific CHEK2 variants in thyroid cancer cases were not reported [13].

\section{Prevalence of germline CHEK2 mutations in thyroid cancer patients versus healthy matched controls}

Six studies compared the prevalence of germline CHEK2 mutations in patients with thyroid cancer with a matched cohort (Table 1).

Cybulski et al. published the first case-control study linking papillary thyroid cancer with an increased prevalence of germline CHEK2 mutations. They found the prevalence of overall CHEK2 mutations was $12,24 \%$ in patients with papillary thyroid cancer versus $5,53 \%$ in matched controls (no statistical analysis available). When considering the truncating mutations separately (IVS2 + $1 \mathrm{G}>\mathrm{A}$ and 1100delC) the authors conclude there is a statistically significant association with thyroid cancer (OR 4,9; $p=0,0006$ ) [7]. This association was corroborated in a larger case-control study by Siolek et al. The prevalence of four different CHEK2 germline mutations was investigated in 468 patients with papillary thyroid cancer versus 468 age- and sex-matched controls. Patients with thyroid cancer had a significantly higher prevalence of truncating CHEK2 mutations (IVS2 + $1 \mathrm{G}>\mathrm{A}, \mathrm{c} .1100 \mathrm{del} C$ or del 5395) than the control group (OR 5,7; $p=0,006$ ) [8]. In the largest case-control study so far, Gasior-Perczak et al. found in the Polish population the CHEK2 c.1100delC mutation to be present in $1 \%$ of papillary thyroid cancer patients (16/1547), and none in 468 healthy controls (no statistical analysis available). No statistically significant association was found between different individual truncating CHEK2 variants and thyroid cancer. When pooling the truncating mutations however, there was a statistically significant association (OR 4,54; 95\%CI $[1,40-14,68] ; p=0,0116)$, which was driven primarily by the IVS2 $+1 G>A$ variant [14] A case-control study of patients with non-anaplastic thyroid cancer in an Iranian population found no germline CHEK2 mutations in cases nor controls, though this probably reflects the low frequency of $C H E K 2$ mutations 
Table 1 Prevalence of CHEK2 mutation in patients with thyroid cancer versus healthy controls based on case-control series. (NA: no data available; OR: odds ratio; Cl: confidence interval)

\begin{tabular}{|c|c|c|c|c|c|c|c|c|c|c|}
\hline \multirow{2}{*}{$\begin{array}{l}\text { Author } \\
\text { Cybulski et al. (7) }\end{array}$} & \multirow{2}{*}{$\begin{array}{l}\text { Population } \\
\text { Polish }\end{array}$} & \multirow{2}{*}{$\begin{array}{l}\text { Tumor Type } \\
\text { Papillary thyroid }\end{array}$} & \multirow{2}{*}{$\begin{array}{l}\text { Investigated Gene } \\
\text { Variant } \\
\text { c.1100delC }\end{array}$} & \multicolumn{2}{|c|}{$\begin{array}{l}\text { Carrier } \\
\text { Frequency in } \\
\text { thyroid cancer } \\
\text { patients }\end{array}$} & \multicolumn{2}{|c|}{$\begin{array}{l}\text { Carrier } \\
\text { Frequency in } \\
\text { healthy } \\
\text { controls }\end{array}$} & \multirow{2}{*}{$\begin{array}{l}\text { OR } \\
2,3\end{array}$} & \multirow{2}{*}{$\begin{array}{l}95 \%-\mathrm{Cl} \\
{[N A]}\end{array}$} & \multirow{2}{*}{$\begin{array}{l}p \text { - } \\
\text { value } \\
0,9\end{array}$} \\
\hline & & & & $1 / 173$ & $(0,57 \%)$ & $\begin{array}{l}10 / \\
4000\end{array}$ & $(0,25 \%)$ & & & \\
\hline & & & $c .444+1 G>A$ & $5 / 173$ & $(2,89 \%)$ & $\begin{array}{l}19 / \\
4000\end{array}$ & $(0,48 \%)$ & 6,2 & {$[N A]$} & 0,0003 \\
\hline & & & C. $470 \mathrm{~T}>\mathrm{C}$ & $15 / 173$ & $(8,67 \%)$ & $\begin{array}{l}192 / \\
4000\end{array}$ & $(4,80 \%)$ & 1,9 & {$[N A]$} & 0,04 \\
\hline \multirow[t]{4}{*}{ Siołek et al. (8) } & Polish & Papillary thyroid & c.1100delC & $1 / 468$ & $(0,21 \%)$ & $0 / 468$ & $(0,00 \%)$ & NA & {$[N A]$} & NA \\
\hline & & & $c .444+1 G>A$ & $10 / 468$ & $(2,14 \%)$ & $1 / 468$ & $(0,20 \%)$ & 10 & {$[1,3-78,1]$} & 0,03 \\
\hline & & & C. $470 \mathrm{~T}>\mathrm{C}$ & $60 / 468$ & $(12,82 \%)$ & $25 / 468$ & $(5,30 \%)$ & 2,8 & {$[0,6-14,8]$} & 0,001 \\
\hline & & & $\begin{array}{l}\text { c.27417113- } \\
27422508 \text { del }\end{array}$ & $6 / 468$ & $(1,28 \%)$ & $2 / 468$ & $(0,40 \%)$ & 3.0 & {$[1,7-4,6]$} & 0,2 \\
\hline \multirow[t]{2}{*}{ Fayaz et al. (15) } & Iranian & Non anaplastic thyroid & c. $444+1 G>A$ & $0 / 100$ & $(0 \%)$ & $0 / 100$ & $(0,00 \%)$ & NA & {$[N A]$} & NA \\
\hline & & & C. $470 \mathrm{~T}>\mathrm{C}$ & $0 / 100$ & $(0 \%)$ & $0 / 100$ & $(0,00 \%)$ & NA & {$[N A]$} & NA \\
\hline Wojcicka et al. (16) & Polish & Papillary thyroid & c. $470 \mathrm{~T}>\mathrm{C}$ & $\begin{array}{l}169 / \\
1700\end{array}$ & $(9,94 \%)$ & $\begin{array}{l}98 / \\
2056\end{array}$ & $(4,70 \%)$ & 2,2 & $\begin{array}{l}{[1,71-} \\
2,86]\end{array}$ & $\begin{array}{l}< \\
0,0001\end{array}$ \\
\hline $\begin{array}{l}\text { Kaczmarek-Rys et al. } \\
\text { (17) }\end{array}$ & Polish & $\begin{array}{l}\text { Papillary and follicular } \\
\text { thyroid }\end{array}$ & C. $470 \mathrm{~T}>\mathrm{C}$ & $51 / 602$ & $(4,49 \%)$ & $42 / 829$ & $(2,53 \%)$ & 1,8 & $\begin{array}{l}{[1,20-} \\
2,72]\end{array}$ & 0,004 \\
\hline \multirow[t]{4}{*}{$\begin{array}{l}\text { Gąsior-Perczak et al. } \\
\text { (14) }\end{array}$} & Polish & Papillary thyroid & c. $470 \mathrm{~T}>\mathrm{C}$ & $\begin{array}{l}189 / \\
1547\end{array}$ & $(12,3 \%)$ & $25 / 468$ & $(5,30 \%)$ & 2,5 & $\begin{array}{l}{[2,47-} \\
3,79]\end{array}$ & $<0,001$ \\
\hline & & & c.1100delC & $\begin{array}{l}16 / \\
1547\end{array}$ & $(1,00 \%)$ & $0 / 468$ & $(0,00 \%)$ & NA & {$[\mathrm{NA}]$} & NA \\
\hline & & & $c .444+1 G>A$ & $\begin{array}{l}18 / \\
1547\end{array}$ & $(1,20 \%)$ & $1 / 468$ & $(0,20 \%)$ & 7,1 & $\begin{array}{l}{[0,95-} \\
52,31]\end{array}$ & 0,056 \\
\hline & & & $\begin{array}{l}\text { c.27417113- } \\
27422508 d e l\end{array}$ & $\begin{array}{l}10 / \\
1547\end{array}$ & $(0,60 \%)$ & $2 / 468$ & $(0,40 \%)$ & 2,1 & {$[0,48-9,40]$} & 0,319 \\
\hline
\end{tabular}

in the Middle Eastern population [15]. Two studies in the Polish population only investigated the I157T variant $[16,17]$.

These studies, together with the three other Polish studies mentioned previously, found an increased I157T carrier frequency in papillary thyroid cancer patients compared to controls with odds ratios between 1,9 to $3,0[7,8,14,16,17]$.

\section{Prevalence of germline CHEK2 variants in thyroid cancer case series}

In a Czech pediatric population of papillary thyroid cancer patients, $7 / 84(8,4 \%)$ had a CHEK2 variant. The majority carried the $\operatorname{I157T}(n=5)$, with one c.1100delC carrier and 1 variant of uncertain significance (p.L467F) [18].

A conference abstract by Kamihara et al. reported genotyping 2678 thyroid cancer patients. In this ethnically more diverse population (66\% Caucasian) CHEK2 was the most frequently mutated gene $(3,1 \%)$. About $90 \%$ of subjects were female, of which $50 \%$ had a history of breast cancer, implying an important selection bias.
The specific CHEK2 mutations were not reported, histological information was incomplete, and there was no control group [19])

\section{Discussion}

Is there a relation between risk of papillary thyroid cancer and germline CHEK2 mutations?

The cross-sectional study of Leedom et al. reports a statistically significant higher incidence of thyroid cancer history in carriers of truncating CHEK2 variants versus non-carriers, but no conclusions can be drawn for papillary thyroid cancer specifically as no pathological details of thyroid cancer are available [11]. In the study by Näslund-Koch et al. there is a higher incidence of thyroid cancer in CHEK2 c.1100delC carriers, though this difference is not reported as statistically significant [10]. These studies are all limited by their retrospective design, which has an inherent reporting bias, and are to be interpreted with caution. It should also be noted that Näslund-Koch only investigated c.1100delC whereas the two other studies investigated all variants. There seems 
to be no difference however in prevalence of thyroid cancer history between different $C H E K 2$ variants $[4,11]$.

Most of the case-control studies were conducted in the same, Polish, population. Here it was repeatedly shown that in patients with papillary thyroid carcinoma, the incidence of CHEK2 truncating variants is significantly higher. There is possibly an elevated risk of thyroid cancers in CHEK2 c. $444+1 \mathrm{G}>\mathrm{A}$ carriers, although the number of carriers in these studies was limited. In other populations however these findings have thus far not been reproduced. Maybe a different environmental or genetic factor could be responsible for the stronger association between $C H E K 2$ variants and thyroid cancer in the Polish population. It has been proposed that differences in genetic background and exposure to environmental risk factors may modify specific risks, which implies that two individuals with the same mutation may face different cancer risks based on cultural background and genetic modifiers, specific to their population. For example, recently it has been reported that the increased risk of breast and prostate cancer associated with the NBN (657del5) founder mutation is modified by the presence of a common missense variant in the NBN gene (E185Q). The elevated cancer risk is limited to biallelic E185Q variant carriers $(\mathrm{OR}=3.6 ; p<0,001)$ and is not elevated in women with other E185Q genotypes $(\mathrm{OR}=1.0 ; p=0,9)$. On itself however NBN E185Q does not predispose to breast or prostate cancer [20].

\section{Should we screen carriers of a CHEK2 c.1100delC or other truncating variants for thyroid cancer?}

Belgian national guidelines for CHEK2 carriers recommend gynaecological follow-up from age 25 and breast cancer screening starting at age 35 in women, yearly PSA and digital prostate exam starting at age 50 in men, and colonoscopy every 5 years from age 40 (or 10y before youngest diagnosis of colorectal cancer in family) in both sexes. Current national and most international guidelines do not recommend screening for thyroid cancer in patients with CHEK2 mutations [21-24]. Only the guidelines of the International Hereditary Cancer Centre propose screening for thyroid cancer in CHEK2 carriers, based on the Polish case-control studies [25]. There is however insufficient evidence to support screening in other populations.

About $5 \%$ of non-medullary thyroid cancer present in familial form. Familial papillary carcinoma is considered when at least 3 first-degree relatives are diagnosed with papillary carcinoma, since a single first-degree relative with thyroid cancer may just be a sporadic event [22].. Current guidelines recommend yearly thyroid ultrasound screening in Cowden syndrome, Familial adenomatous polyposis (FAP), and the more rare Carney complex, Werner syndrome and DICER1 syndromes $[22,26]$. In
Cowden syndrome the lifetime risk of developing thyroid cancer is $6-35 \%$, and annual screening is recommended [22, 26-28]. In FAP the absolute lifetime risk of thyroid cancer is much lower at $1-8 \%$, nonetheless current guidelines recommend screening [22, 24]. However, screening in FAP is under debate considering low mortality due to thyroid cancer in this population $(2 / 4820$ patients; 0,04\%) [29].

To justify a screening program a disease should be frequently occurring, screening should result in cancer detection at an earlier stage leading to a potentially curable treatment and benefits of early detection should outweigh the risks [29].

Current evidence suggests a low absolute risk of thyroid cancer in CHEK2 mutation carriers, and these are mostly of differentiated, non-medullary histology. The available evidence likely overestimates the risk of developing thyroid cancer, because of selection and reporting bias. Furthermore, the findings in the Polish population have not been validated in other populations. There are no data available on thyroid specific mortality in CHEK2 mutation carriers, nor is it clear if thyroid cancer in this population is more aggressive or presents at an earlier age. Thyroid carcinoma in general is associated with a high 5 year overall survival of 96 , and $>90 \%$ of cases are diagnosed at an early, curable stage [30,31]. Screening in comparable selected populations with low absolute prevalence results in a higher rate of papillary thyroid cancer detection and potentially harmful interventions, but no reduction in mortality [29].

\section{Conclusion}

There is a low level of evidence for a slightly higher incidence of thyroid cancer in patients with (likely) pathogenic CHEK2 mutations compared to non-carriers. Current guidelines do not recommend systematic screening. To evaluate whether systematic screening for thyroid cancer should be recommended in CHEK2 carriers, a prospective cohort study, comparing the incidence of thyroid cancer in CHEK2 mutation carriers and non-carriers should be set up, preferably including different ethnicities.

\section{Authors' contributions}

KK performed the literature search, drafted the manuscript, and approved the submitted version. Authors RDP and EN revised the manuscript and approved the submitted version. All authors are personally accountable for their own contributions.

\section{Funding}

Funding of the study was not applicable.

Availability of data and materials

All data analysed in this study are available in the manuscript. 


\section{Declarations}

\section{Ethics approval and consent to participate}

This study was approved by the ethics committee of Ghent University Hospital.

\section{Consent for publication}

The patient consented to participate and signed a written informed consent form concerning publication of her medical history.

\section{Competing interests}

The authors report no competing interests.

\section{Author details}

${ }^{1}$ Department of Medical Oncology, University Hospital Ghent, Ghent, Belgium. '2Department of Medical Genetics, University Hospital Ghent, Ghent, Belgium.

Received: 2 July 2021 Accepted: 13 January 2022

Published online: 31 January 2022

\section{References}

1. Jackson SP, Bartek J. The DNA-damage response in human biology and disease. Nature. 2009;461(7267):1071-8. https://doi.org/10.1038/nature08467.

2. Bartek J, Lukas J. Chk1 and Chk2 kinases in checkpoint control and cancer. Cancer Cell. 2003;3(5):421-9. https://doi.org/10.1016/S1535-6108(03)00110-7.

3. Stolarova L, Kleiblova P, Janatova M, Soukupova J, Zemankova P, Macurek L, et al. CHEK2 germline variants in Cancer predisposition: stalemate rather than checkmate. Cells. 2020;9(12):1-43. https://doi.org/10.3390/cells9122675.

4. Sutcliffe EG, Stettner AR, Miller SA, Solomon SR, Marshall ML, Roberts ME, et al. Differences in cancer prevalence among CHEK2 carriers identified via multi-gene panel testing. Cancer Genet. 2020;246-247:12-7. https://doi. org/10.1016/j.cancergen.2020.07.001.

5. Weischer M, Bojesen SE, Tybjærg-Hansen A, Axelsson CK, Nordestgaard BG. Increased risk of breast J Clin Oncolcancer associated with CHEK2*1100delC 2007:25(1):57-63. https://doi.org/10.1200/JCO.2005.05.5160.

6. Meijers-Heijboer H, Van den Ouweland A, Klijn J, Wasielewski M, De Shoo A, Oldenburg $\mathrm{R}$, et al. Low-penetrance susceptibility to breast cancer due to CHEK2*1100delC in noncarriers of BRCA1 or BRCA2 mutations: the CHEK2breast cancer consortium. Nat Genet. 2002;31(1):55-9. https://doi.org/10.103 8/ng879.

7. Cybulski C, Górski B, Huzarski T, Masojć B, Mierzejewski M, Dębniak T, et al. CHEK2 is a multiorgan cancer susceptibility gene. Am J Hum Genet. 2004; 75(6):1131-5. https://doi.org/10.1086/426403

8. Siołek M, Cybulski C, Gasior-Perczak D, Kowalik A, Kozak-Klonowska B, Kowalska A, et al. CHEK2 mutations and the risk of papillary thyroid cancer Int J Cancer. 2015:137(3):548-52. https://doi.org/10.1002/ijc.29426.

9. Gąsior-Perczak D, Kowalik A, Walczyk A, Siołek M, Gruszczyński K, Pałyga I, et al. Coexisting Germline CHEK2 and Somatic BRAFV600E Mutations in Papillary Thyroid Cancer and Their Association with Clinicopathological Features and Disease Course. Cancers. 2019;11(11):1744.

10. Näslund-Koch C, Nordestgaard BG, Bojesen SE. Increased risk for other cancers in addition to breast Cancer for CHEK2 * 1100delC heterozygotes estimated from the Copenhagen general population study. J Clin Oncol. 2016;34(11):1208-16. https://doi.org/10.1200/JCO.2015.63.3594.

11. Leedom TP, Laduca H, Mcfarland R, Li S, Dolinsky JS, Chao EC. Breast cancer risk is similar for CHEK2 founder and non-founder mutation carriers. Cancer Genet. 2016;209(9):403-7. https://doi.org/10.1016/j.cancergen.2016.08.005.

12. Syrenicz A, Koziolek M, Rudnicka M, Sieradzka A, Cybulski C, Kiedrowicz B. Carrying mutations truncating CHEK2 protein predisposes to thyroid neeoplasms - preliminary report. In: 20th European Congress of Endocrinology. Barcelona; 2018. p. GP238. https://doi.org/10.1530/endoabs. 56.GP238.

13. Blankenship L, Yadav S, Yumpo Cardenas P, Zakalik D. Abstract P4-06-03: Characteristics of CHEK2 mutation carriers in a large academic health center in Michigan. In: Poster Session Abstracts. American Association for Cancer Research; 2018. p. P4-06-03-P4-06-03.

14. Gąsior-Perczak D, Kowalik A, Gruszczyński K, Walczyk A, Siołek M, Pałyga I, et al. Incidence of the CHEK2 germline mutation and its impact on Clinicopathological features, treatment responses, and disease course in patients with papillary thyroid carcinoma. Cancers. 2021 Jan 26;13(3):470. https://doi.org/10.3390/cancers13030470.

15. Fayaz S, Fard-esfahani P, Torbati PM. Lack of CHEK2 gene mutations in differentiated thyroid carcinoma patients using high resolution melting analysis. Asian Pacific J cancer Prev. 2014;15(November 2018):5018-31. https://doi.org/10.7314/APJCP.2014.15.12.5019.

16. Wójcicka A, Czetwertyńska M, Świerniak M, Długosińska J, Maciąg M, Czajka A, et al. Variants in the ATM-CHEK2-BRCA1 axis determine genetic predisposition and clinical presentation of papillary thyroid carcinoma. Genes Chromosomes Cancer. 2014 Jun;53(6):516-23. https://doi.org/10.1 002/gcc.22162.

17. Kaczmarek-Ryś M, Ziemnicka K, Hryhorowicz ST, Górczak K, HoppeGołebiewska J, Skrzypczak-Zielińska M, et al. The c.470 T > C CHEK2 missense variant increases the risk of differentiated thyroid carcinoma in the great Poland population. Hered Cancer Clin Pract. 2015;13(1):1-9. https:// doi.org/10.1186/s13053-015-0030-5.

18. Pekova B, Dvorakova S, Sykorova V, Vacinova G, Vaclavikova E, Moravcova J, et al. Somatic genetic alterations in a large cohort of pediatric thyroid nodules. Endocr Connect. 2019;8(6):796-805. https://doi.org/10.1530/EC-19-0069.

19. Kamihara J, LaDuca H, Dalton E, Speare V, Garber JE, Black MH. Germline mutations in cancer predisposition genes among patients with thyroid cancer. J Clin Oncol. 2017:35(15 suppl):1581.

20. Rusak B, Kluźniak W, Wokołorczyk D, Stempa K, Kashyap A, Rudnicka H, et al. Allelic modification of breast cancer risk in women with an NBN mutation. Breast Cancer Res Treat. 2019;178(2):427-31. https://doi.org/10.1007/s10549-019-05391-w.

21. Tung NM, Boughey JC, Pierce LJ, Robson ME, Bedrosian I, Dietz JR, et al. Management of hereditary breast cancer: American society of clinical oncology, American society for radiation oncology, and society of surgical oncology guideline. J Clin Oncol. 2020;38(18):2080-106. https://doi.org/10.12 00/JCO.20.00299.

22. National Comprehensive Cancer Network. Thyroid carcinoma version 3.2020 2021 [cited 2021]. Available from: https://www.nccn.org/professionals/ physician_gls/pdf/thyroid.pdf

23. Belgian Society for Human Genetics. Belgian guidelines for Managing Hereditary Breast and Ovarian Cancer. 2020 [cited 2021]. Available from: https://www.college-genetics.be/assets/recommendations/fr/guidelines/ HBOC\%20management\%20criteria.pdf.

24. Filetti S, Durante C, Hartl D, Leboulleux S, Locati LD, Newbold K, et al. Thyroid cancer: ESMO clinical practice guidelines for diagnosis, treatment and follow-up. Ann Oncol. 2019;30(12):1856-83. Available from: https://doi. org/10.1093/annonc/mdz400.

25. Kurzawski G, Suchy J, Cybulski C, Matyjasik J, Dẹbniak T, Górski B, et al. DNA testing for variants conferring low or moderate increase in the risk of cancer. Hered Cancer Clin Pract. 2008;6(2):84-7. https://doi.org/10.1186/1 897-4287-6-2-84

26. Haugen BR, Alexander EK, Bible KC, Doherty GM, Mandel SJ, Nikiforov YE, et al. 2015 American Thyroid Association management guidelines for adult patients with thyroid nodules and differentiated thyroid Cancer: the American Thyroid Association guidelines task force on thyroid nodules and differentiated thyroid Cancer. Thyroid. 2016;26(1):1-133. https://doi.org/10.1 089/thy.2015.0020

27. Tischkowitz M, Colas C, Pouwels S, Hoogerbrugge N. Cancer surveillance guideline for individiuals with PTEN hamartoma tumour syndrome (PHTS). Eur J Hum Genet. 2020;28(June):1387-93. https:/doi.org/10.1038/s41431-020-0651-7.

28. Stjepanovic N, Moreira L, Carneiro F, Balaguer F, Cervantes A, Balmana J, et al. Hereditary gastrointestinal cancers : ESMO Clinical Practice Guidelines for diagnosis, treatment and follow-up. Ann Oncol. 2019;30(August):155871. https://doi.org/10.1093/annonc/mdz233.

29. Lamartina L, Grani G, Durante C, Filetti S, Cooper DS. Screening for differentiated thyroid cancer in selected populations. Lancet Diabetes Endocrinol. 2020;8(1):81-8. https://doi.org/10.1016/S2213-8587(19)30324-9.

30. Dal Maso L, Tavilla A, Pacini F, Serraino D, van Dijk BAC, Chirlaque MD, et al. Survival of 86,690 patients with thyroid cancer: a population-based study in 29 European countries from EUROCARE-5. Eur J Cancer. 2017;77:140-52. https://doi.org/10.1016/j.ejca.2017.02.023.

31. Belgian Cancer Registry. Cancer Fact Sheet Thyroid Cancer Incidence Year 2018. Brussels: 2020

\section{Publisher's Note}

Springer Nature remains neutral with regard to jurisdictional claims in published maps and institutional affiliations. 